\title{
Experimental investigation of slug pattern in a horizontal two-phase flow
}

\author{
I. Belgacem ${ }^{1}$, Y. Salhi ${ }^{1}$, E.-K. SI-Ahmed ${ }^{1,2}$, J. Legrand ${ }^{2}$ \\ \& J. M Rosant ${ }^{3}$ \\ ${ }^{1}$ Laboratoire de Mécanique des Fluides Théorique et Appliquée, \\ Faculté de Physique, USTHB, Algeria \\ ${ }^{2}$ GEPEA, Université de Nantes, CNRS, St Nazaire, France \\ ${ }^{3}$ Laboratoire de Mécanique des Fluides, CNRS, \\ Ecole Centrale Nantes, France
}

\begin{abstract}
Gas-liquid two-phase flow occurs in a wide range of engineering applications in various industrial fields. For example, without being exhaustive, in the chemical and process industry, a two-phase flow is encountered in boilers, condensers, evaporators and reactors. In the petroleum industry, a two-phase flow is observed during the production and transportation of oil and gas.

Among flow patterns encountered in field operations, the slug flow appears to be dominant in horizontal and near horizontal pipelines, and is, unfortunately, the most complicated one. It is characterized by an alternate flow of liquid slugs and gas pockets, resulting in inherently unsteady hydrodynamic behavior. All the important design variables, such as gas and liquid velocity profiles, liquid holdup distribution and pressure drop vary axially and radially and exhibit fluctuations, even when the inlet liquid and gas flow rates are constant. This makes prediction of slug flow characteristics complex and challenging.

This paper is therefore devoted to slug flow in horizontal pipelines and attempts to address the above-cited points. Specifically, the study aims to develop a map of flow regimes then acquire pertinent slug flow data. For that purpose, an experimental test rig was built-up to examine the process of slug initiation in a $40 \mathrm{~mm}$ i.d and a $14 \mathrm{~m}$ length horizontal pipeline. Two-phase cocurrent air-water pressure gradients were measured. Most of the data recorded correspond to the slug flow region, noting then rapid fluctuations in pressure.
\end{abstract}


Data on slug initiation, pressure variation as well as slug frequency and length are investigated and reported hereafter.

Keywords: two phase flow, flow map, slug flow, horizontal pipe, pressure, frequency, slug length.

\section{Introduction}

Several flow regimes occur in multiphase flows including stratified, intermittent and annular flow. Plug/ slug two-phase flow pattern, which is commonly defined as intermittent flow, is frequently encountered in industrial applications. Relevant examples are found in oil/gas production and transport lines. Classical flow maps (e.g. Baker [1], Mandhane et al. [2], Taitel and Dukler [3]), indicate that the intermittent regime exists for a wide range of gas and liquid flow rates in a horizontal two-phase flow configuration.

Intermittent flows have been studied, both experimentally and theoretically, for many years. However, a full understanding of the nature of such flow has not been reached. This is mainly due to its complexity, irregularity and intermittency. Slug flow in extreme situations can be the cause of the damage of pipe systems or devices for several reasons among one may point out:

-Large variations in gas and liquid flow rates (the latter, in the slug, being manifold the average value of the liquid phase).

-Considerable momentum of long slugs (for instance, considerable forces on pipe bends).

-Large pressure drops (high pressure gradients accompany the liquid slug).

-Resonance problems in case of slug frequency close to the resonant frequency of the multiphase pipe system.

-In hydrocarbon production lines, where the fluids transported may contain corrosive agents $\left(\mathrm{H}_{2} \mathrm{O}, \mathrm{H}_{2} \mathrm{~S}\right.$ and $\left.\mathrm{CO}_{2}\right)$ slug flow is found to present safety risks due to damage imposed on pipe walls.

For that purpose, accurate knowledge on the transition from stratified to slug flow as well as slug pressure, frequency and length variations happens to be necessary in order to be able to model and predict adequately this flow regime That constitute the main objective of this work. A flow regime was first build up as a mean of defining the transition from stratified to slug flow. Then the above cited parameters are statistically investigated.

\section{Experimental facility and measurement techniques}

The experimental set-up used to detect slugs is sketched in Fig. 1. The loop is adapted to generate a concurrent gas-liquid two-phase flow. It operates in closed circuit for the liquid component, open for the gas component. The experiments were conducted in a horizontal pipe of $0.04 \mathrm{~m}$ diameter and a $14 \mathrm{~m}$ length. . The liquid flow is delivered by a centrifugal Noryle pump, the nominal operating point gives a volume flow rate $10 \mathrm{~m}^{3} / \mathrm{h}$ for a delivery height of $9 \mathrm{~m}$. The air is provided by a compressor where air filters are mounted in order to remove all traces of impurities and oil in the air. Both fluids air/water arrive in a cylindrical 
mixing chamber feeding then, with the resulting two-phase component, the pipe made of Plexiglas. Prior to the recordings, the horizontality was first set; avoiding any transition due to the effect of the pipe inclination (Salhi et al. [4]). Visualization of the flow regime is achieved at $7 \mathrm{~m}$ from the inlet of the pipe using a Canon HG20 camera (1920*1080 full HD24 bits/s) with high resolution. Gas flow measurements, ranging from $10 \mathrm{l} / \mathrm{mn}$ up to $400 \mathrm{l} / \mathrm{mn}$, are performed by two Rota meters VMRP010092 and VMRP010083 type. The liquid rate ranging from $10 \mathrm{l} / \mathrm{mn}$ to $68 \mathrm{l} / \mathrm{mn}$ are measured by an ultrasonic flow meter type PT878 portable.

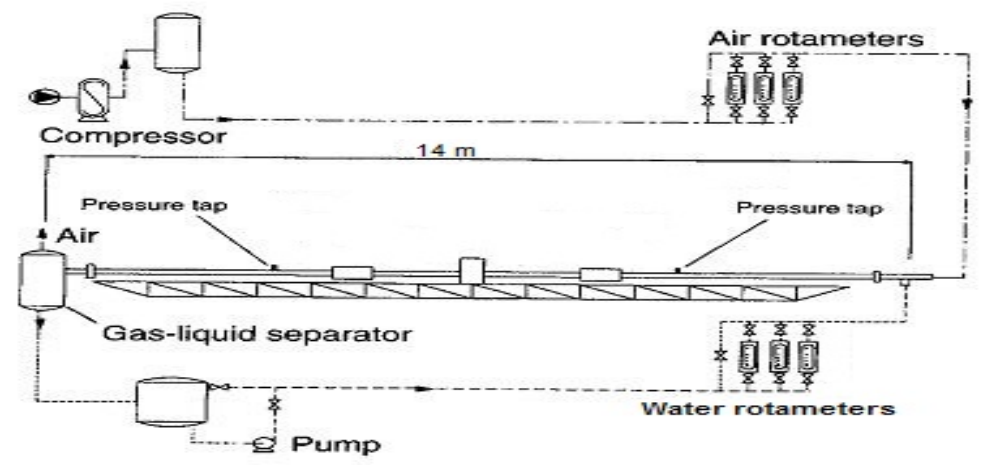

Figure 1: Description of the experimental loop.

\section{Results and discussion}

\subsection{Flow regime}

When gas and liquid flow simultaneously in a pipe, both phases can distribute in a variety of flow configurations, according to the operating variables (gas and liquid flow rates), geometry (pipe diameter and inclination angle) and the fluids physical properties. For the purpose of identifying the flow, it is important to define clearly, first, a flow pattern classification.

In concurrent horizontal and near horizontal pipelines, classical flow patterns (as depicted in fig. 2) were adopted and classified as follows:

Stratified flow: liquid flows at the bottom of the pipe with gas at the top.

Wavy flow: once increasing the gas velocity in a stratified flow, waves are formed on the interface and travel in the direction of the flow. The amplitude of the waves is notable and depends on the relative velocity of the two phases. However, their crests do not reach the top of the tube.

Elongated bubbles (plug flow): this regime has liquid plugs that are separated by elongated bubbles. The diameters of the elongated bubbles are much smaller than the tube such that the liquid phase is continuous along the bottom of the tube below the elongated bubbles. 
Slug flow: at higher gas velocities, the diameters of the elongated bubbles become similar in size to the channel height. The liquid slugs separating such elongated bubbles can also be described as large amplitude waves.

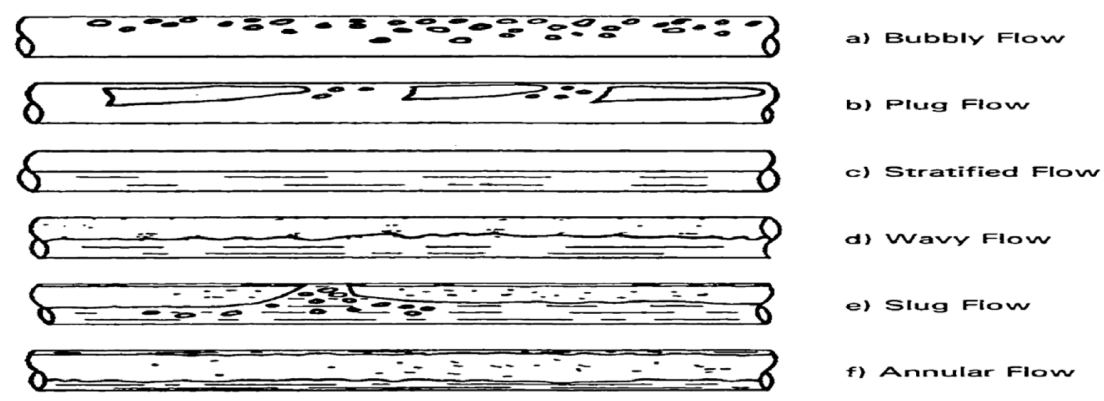

Figure 2: $\quad$ Some flow patterns in horizontal pipe.

\subsubsection{Detection of flow regime}

Flow pattern characterization in two-phase flow is in general obtained by visual observation. In this work, detection of flow was carried out using two methods: visualization and conductivity probes technique, this method was used by Solomon [6] and Griffith [7]. They applied this technique using a single conductivity probe. Friori and Bergles [8] and Bergles et al. [9] also used a conductivity probe for boiling flows in horizontal tubes; they used a single central probe and were able to detect differences among bubbly, slug and annular flow. Barnea et al. [10] identified the flow patterns in two phase horizontal and upward flows. The results show that this system is very well suited to distinguish among flow patterns. This method is well suited to opaque systems.

The technique of conductivity probes is based on the significantly different electrical conductivity of air and water. Probes were placed at different position for the purpose of determining the flow pattern. Representative runs and digital images taken using Canon digital camera for each flow regimes observed in our experimental loop are presented in fig. 3 .

\subsubsection{Flow regime map}

In order to enhance the confidence level of our experimental investigation, a flow regime map was compiled. The experimental data, obtained for isothermal condition, is reported in Figure 4. The data (shown as points) is plotted $\left(\mathrm{J}_{\ell}\right.$ and $\left.\mathrm{J}_{\mathrm{g}}\right)$ in comparison to the Mandhane et al. [2] transition lines for horizontal flow. Following the flow regime map, a study of the characteristics of slug flow in the $0.04 \mathrm{~m}$ pipeline was carried out. 

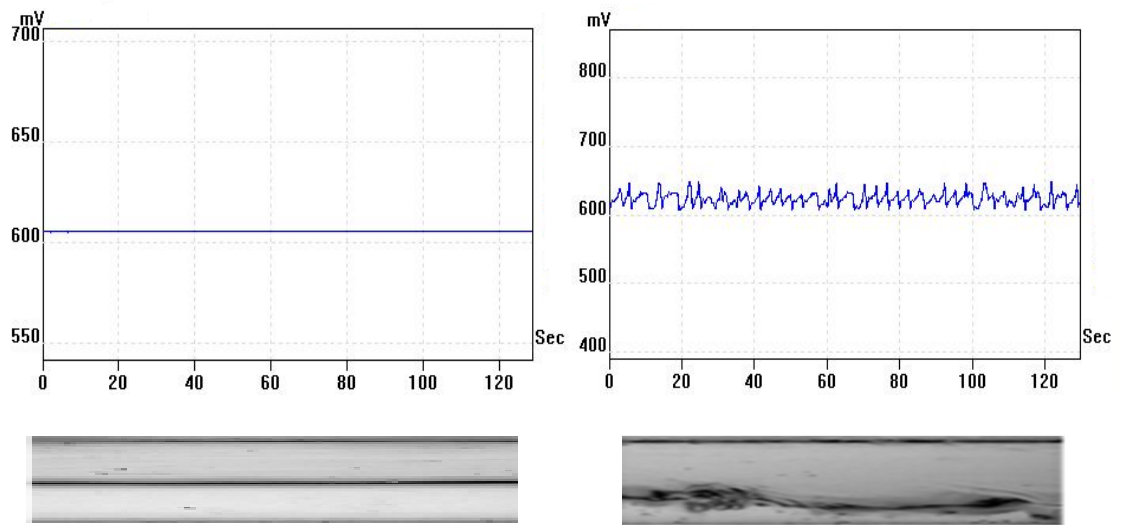

(a)

(b)

$\mathrm{Jg}=0,53 \mathrm{~m} / \mathrm{s} \quad \mathrm{J}_{\ell}=0,1 \mathrm{~m} / \mathrm{s}$

$\mathrm{Jg}=3,15 \mathrm{~m} / \mathrm{s} \quad \mathrm{J}_{\ell}=0,12 \mathrm{~m} / \mathrm{s}$

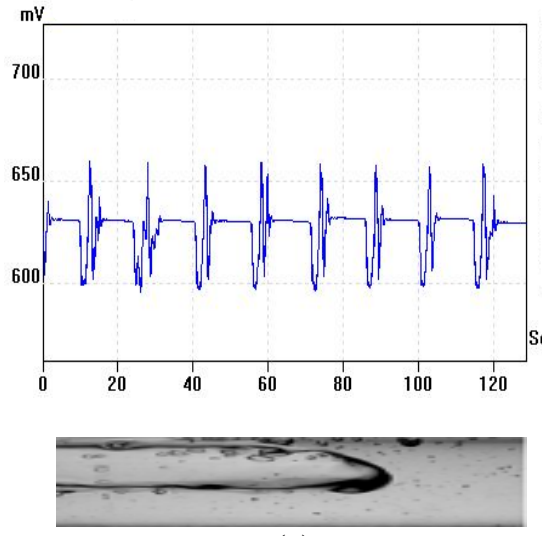

(c)
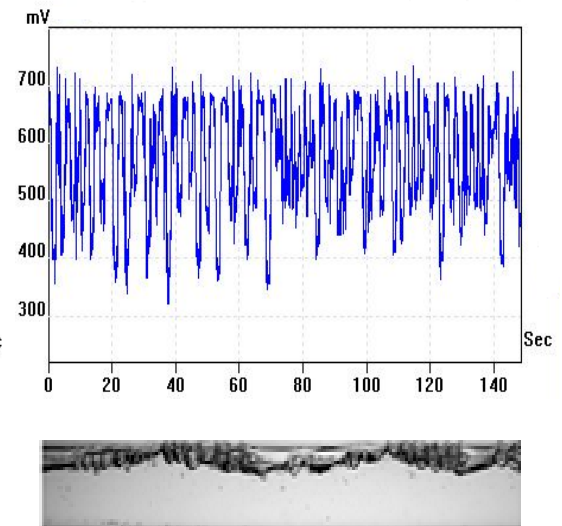

(d)

Figure 3: Flow pattern in $0.04 \mathrm{~m}$ id horizontal pipe. (a) Stratified flow; (b) Wavy flow; (c) Elongated bubble flow; (d) Slug flow. 


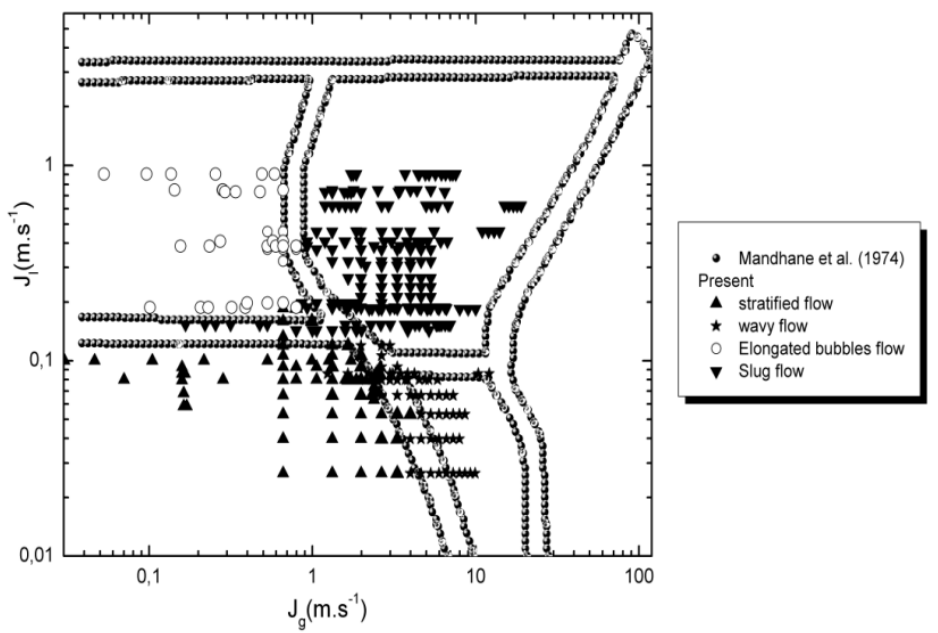

Figure 4: $\quad$ Flow pattern map for $\mathrm{D}=0.04 \mathrm{~m}$ horizontal pipeline.

\subsection{Slug initiation}

When gas and liquid flow in a pipeline, a slug pattern, for which aerated blocks of liquid bridging the whole cross section and moving intermittently downstream, can be observed. The way to which the slugs are formed is very important in predicting the conditions for slug pattern initiation and frequency.

In these experiments the observed conditions leading to slugging initiation of are presented in Fig. 5. This is given as the critical superficial liquid velocity versus the superficial gas velocity (slug flow exists above and stratified flow below the points). For comparison, results obtained by Lin and Hanratty [11] are also included.

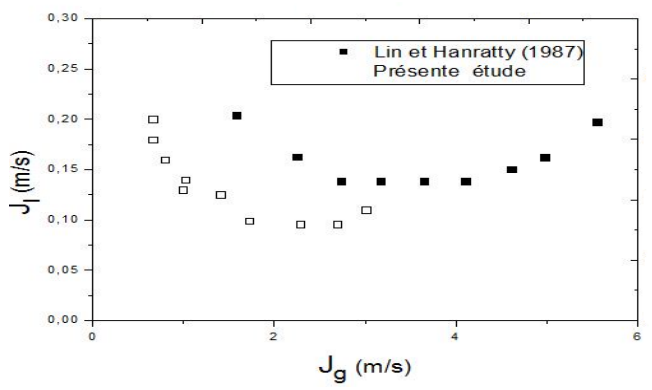

Figure 5: $\quad$ Conditions for the transition from stratified flow to a slug flow.

Once formed, slug initially grows in length, with front traveling faster than the tail. It is possible for a slug to continue growing all the way along the pipe; this typically occurs for the first slug initiated in a stratified system. 


\subsection{Slug flow parameters}

Some of the most relevant properties of slug flow will be examined in the present subsection such as pressure gradient, slug frequency and slug length. Few theoretical methods are available for the prediction of these parameters. Instead, they are generally given by empirical relations based on limited data sets. As a result, the derived relationships are only truly applicable to a specific geometry and fluid pair.

\subsubsection{Pressure variation}

Pressure gradients were measured with a capacitive differential pressure transducer. The taps were placed at $5.29 \mathrm{~m}$ from the entrance of the test section. Measurements of the pressure fluctuations according to the superficial gas velocity, presented in Fig. 6, prove that the reduction in $\mathrm{J}_{\mathrm{g}}$ is accompanied by a progressive reduction in the amplitude of the pressure fluctuation. By analyzing the signals of pressure, it is recorded that the fall of pressure of the film zone between two slugs can be neglected compared with that produced in the zone of mixture (Taitel and Dukler [12]).

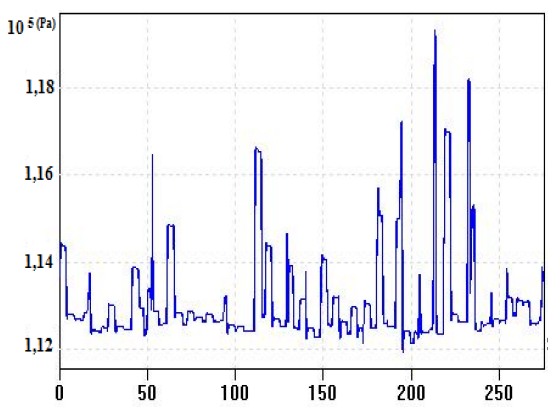

(a) $\mathrm{J}_{\mathrm{g}}=1,18 \mathrm{~m} / \mathrm{s} \quad \mathrm{J}_{\ell}=0,19 \mathrm{~m} / \mathrm{s}$

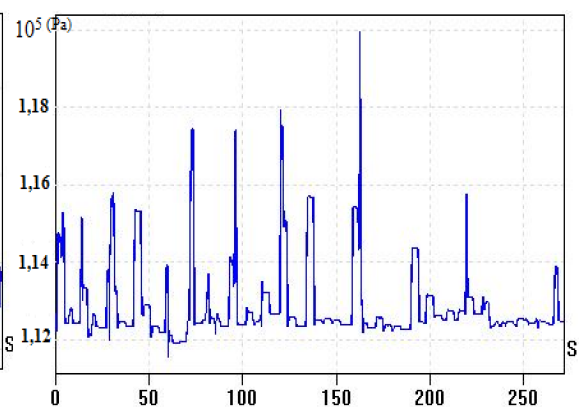

(b) $\mathrm{J}_{\mathrm{g}}=2,25 \mathrm{~m} / \mathrm{s} \quad \mathrm{J}_{\ell}=0,19 \mathrm{~m} / \mathrm{s}$

Figure 6: $\quad$ Pressure variation for different superficial gas velocities.

\subsubsection{Slug frequency}

Several correlations have been developed to predict slug frequency defined as inverse of the slug period defined as the time that a slug unit needs to pass through the measuring device at a certain position from the inlet. A substantial amount of literature is available for predicting slug frequency; Al-Safran [13] provides an extensive literature review on frequency model ranging from simple correlations such as Gregory and Scott [14] and Heywood and Richardson [15] to more complicated ones that take into account the pipe length and mechanistic variables (Woods and Hanratty [16]).

The frequency of slugging was determined by treatment of the electric signal tension delivered by the piezoelectric pressure pick-up using a method similar to that proposed by Lin and Hanratty [11], Fan et al. [17], Woods and Hanratty [16]. According to these authors the onset of a slug in a point is accompanied by a sudden increase of the liquid and pressure levels. Therefore, based on the 
linear relation binding the pressure to the electric tension delivered by the sensor, the recorded peaks of tension reveal the passage of slugs. The slug frequencies are measured, accordingly, over time duration of 272 seconds. The results were then corroborated by counting the slugs during the visioning of the videos recorded simultaneously with the acquisition of the signal delivered by the sensor.

Figs. 7(a) and (b) show the effect of superficial gas velocity (Jg) for various superficial liquid velocities $\left(\mathrm{J}_{\ell}\right)$ on the evolution of the slugging frequency. In all cases, the frequency depends only slightly on superficial gas velocity (Fig. 7(a)). In addition, the frequency of the slugs increases linearly with $\mathrm{J}_{\ell}$ (Fig. 7(b)) and does not seem to be affected by the increase of Jg as reported by Wang et al. [18] and Salhi [19].

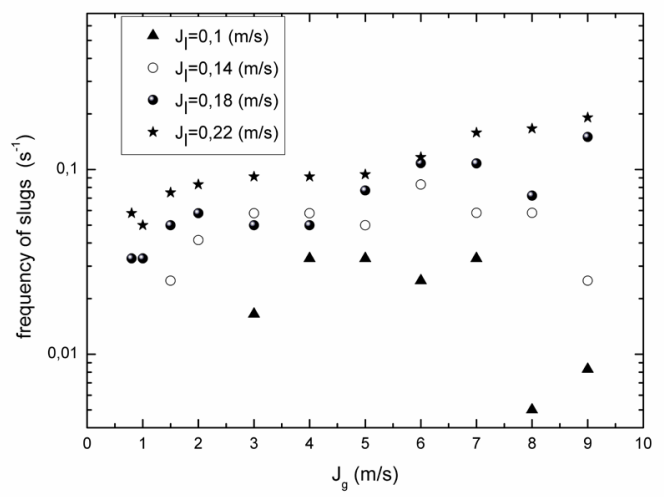

(a)

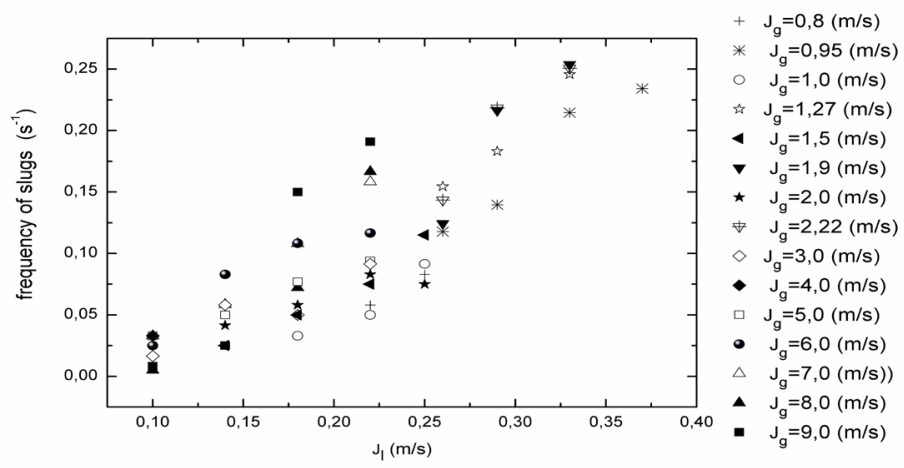

(b)

Figure 7: (a) Frequency of the slugs according to the superficial gas velocity for various superficial liquid velocities; (b) Frequency of the slugs according to the superficial liquid velocity for various superficial gas velocities. 


\subsubsection{Slug length}

The length of the slugs was determined by the correlation of Taitel and Dukler [12] and by Andreussi et al. [20]. The latter connected the length $L_{m b}$ to the frequency $f$, for an intermittency factor $I$. Intermittency $I$ is defined as the time fraction a slug is observed by a stationary observer:

$$
I=\frac{f \cdot L_{m b}}{C}
$$

The intermittency can be very roughly approximated as:

$$
\mathrm{I} \sim \frac{J_{\ell}}{J_{\ell}+J_{g}}
$$

Furthermore, a number of studies (for example, Woods and Hanratty [21]) show that:

$$
C=1.2\left(J_{\ell}+J_{g}\right)
$$

We noted that the length of the slugs does not depend exclusively on the outputs of liquid and gas. Certain authors noted that the average length of the slugs varies little according to the velocity of mixture for air-water flow in horizontal pipeline. As an example, Dukler and Hubbard [22] then Andreussi and Bendiksen [23] observed that $L_{m b}$ varies from 12 to 24d, of 12 until 30d for Nicholson et al. [24], Nydal et al. [25] finds that $L_{m b}$ varies from 15 until 20d, it is $13,63 d$ until 29,31d for Salhi [19]. In our case, the average length of a slug varies between $12,77 \mathrm{~d}$ and $33,24 \mathrm{~d}$, thus our results are slightly higher than those of Nicholson et al. [24] and Salhi [19]. Table 1 shows the mean stable slug lengths observed by different authors.

Table 1: $\quad$ Variation of slug length.

\begin{tabular}{|c|c|c|}
\hline Etude & $L_{m b}$ & $\left(L_{m b} / D\right)_{m o y}$ \\
\hline Dukler and Hubbard [22] & $12-24 \mathrm{~d}$ & 18 \\
\hline Andreussi and Bendiksen [23] & $12-24 \mathrm{~d}$ & 18 \\
\hline Nicholson et al. [24] & $12-30 \mathrm{~d}$ & 21 \\
\hline Nydal et al. [25] & $15-20 \mathrm{~d}$ & 17.5 \\
\hline Salhi [19] & $13.63-29.31 \mathrm{~d}$ & 21.70 \\
\hline Present work & $12.77-33.24 \mathrm{~d}$ & 23.005 \\
\hline
\end{tabular}

Brill et al. [26] were the first to suggest that the behavior length of the slugs follows a logarithmic distribution. It is important to point out that the average length of the slug's $L_{m b}$ decreases when the superficial gas velocity increases (Figs. 8(a) and (b)). 


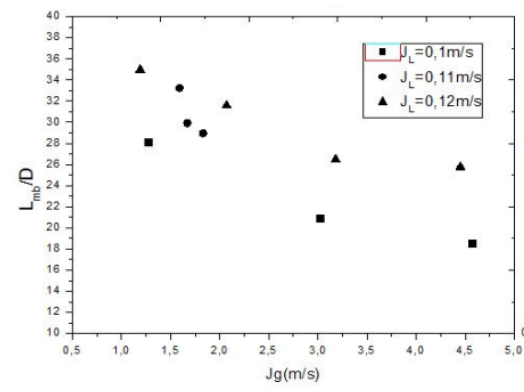

(a)

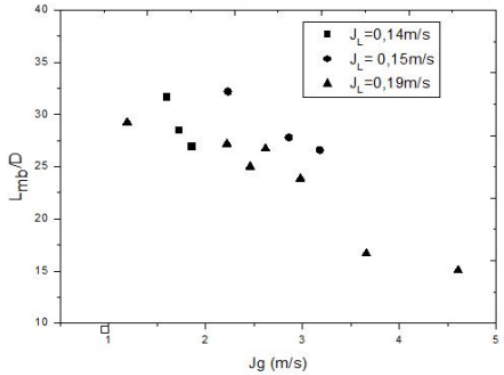

(b)

Figure 8: Average slug lengths, with respect to the superficial gas velocity, for various superficial liquid velocities.

\section{Concluding remarks}

In this work, an experimental study of the slug flow in horizontal pipe was presented. The interest was focused, essentially, on pressure variations, frequency as well as length of slugs. The followings remarks hold:

- The reduction in superficial gas velocity is accompanied by a progressive reduction in the amplitude of the fluctuations in pressure.

- The slug frequency was invariant with pressure.

- $\quad$ The slug frequency of the slugs increases linearly with superficial liquid velocities.

- $\quad$ The slug's length decreases when superficial gas velocity increases.

\section{References}

[1] Baker, O. 1954. Simultaneous flow of oil and gas. Oil and Gas J. 53, 185195.

[2] Mandhane, J.M., Gregory, G.A. and Aziz, K. 1974. A flow pattern map for gas-liquid flow in horizontal pipes. Int. J. Multiphase flow 1, 537-553.

[3] Taitel, Y and Dukler, A.E. 1976. A model for predicting flow regime transitions in horizontal and near horizontal gas-liquid flow. AIChE Jl 22, 47-55.

[4] Salhi, Y., Si-Ahmed, E.K., Legrand, J. and Degrez, G. 2010. Stability analysis of inclined stratified two-phase gas-liquid flow. Nuclear Engineering and Design, vol. 240, 1083-1096.

[5] Hewitt, G.F. and N.S. Hall-Taylor 1970. Annular Two-Phase Flow, Chapters 2, Pergamon Press.

[6] Solomon, J.V, 1962. Construction of a two-phase flow regime transition detector. M.Sc. Thesis, Mech. Eng. Dept, MIT.

[7] Griffith, P. 1964. Two-phase flow regime detecting. ASME paper 64 NA/HT.43. 
[8] Friori, M.P and Bergles, A.E. 1966. A study of boiling water flow regimes at low pressure. Rep. 5382-40, Dept. of Mechanical engineering, MIT.

[9] Bergles, A.E., Lopina, R.F., and Friori, M.P. 1967. Critical heat flux and flow pattern observation for low pressure water flowing in tubes. J. Heat Transfer 89, 69-74.

[10] Barnea, D., Shoham, O., Taitel, Y. 1980. Flow pattern characterization in two -phase flow by electrical conductance probe. Int. J. Multiphase flow 6,387-397.

[11] Lin, P.Y. and T.J. Hanratty 1987a. Detection of Slug Flow from Pressure Measurements, Int. J. of Multiphase Flow, Vol. 13, No. 1, pp. 13-21.

[12] Taitel, Y. and A.E. Dukler 1977. A Model For Slug Frequency During Gasliquid Flow in Horizontal and Near-Horizontal Gas-Liquid Flow, Int. J. of Multiphase Flow, Vol. 19, No. 5, pp. 829-838.

[13] Al-Safran, E. 2009. Investigation and prediction of slug frequency in gas/liquid horizontal pipe flow. J. of Petroleum Science and Engineering 69, 143-155.

[14] Gregory, G., Scott, D. 1969. Correlation of liquid slug velocity and frequency in horizontal co-current gas-liquid slug flow. AICHE J. 15(6), 933-935.

[15] Heywood, N., Richardson, J. 1979. Slug flow of air-water mixtures in a horizontal pipe: determination of liquid holdup by gamma-ray absorption. C. Chem. Eng. Sci. 34, 17-30.

[16] Woods, B.D., Hanratty, T.J. 1999. Influence of Froude number on physical processes determining frequency of slugging in horizontal gas-liquid flows. Int. J. Multiphase Flow vol. 25, pp. 1195-1223.

[17] Fan, Z., Lusseyran, F., Hanratty, T.J. 1993. Initiation of slugs in horizontal gas-liquid flows. AIChE Journal 39 (11), pp. 1741-1753.

[18] Wang, X., Guo, L., Zhang, X. 2007. An experimental study of the statistical parameters of gas-liquid two-phase slug flow in horizontal pipeline. Int. J. of Heat and Mass Trans. 50, 2439-2443.

[19] Salhi, Y. 2010. Contribution théorique et expérimentale à l'étude des phénomènes de transition d'un écoulement stratifié à l'écoulement poche/bouchon dans une conduite horizontale en présence de singularité. $\mathrm{PhD}$ thesis, U.S.T.H.B.

[20] Andreussi, P., Minervini, A., Paglianti, A. 1993. Mechanistic model of slug flow in near-horizontal pipes. AIChE J. 39, 1281-1291.

[21] Woods, B.D., Hanratty, T.J. 1996. Relation of slug stability to shedding rate. Int. J. of Multiphase Flow, 22, 809-829.

[22] Dukler, A.E. and M.G. Hubbard 1975, A Model for gas-liquid slug flow in horizontal and near horizontal tubes, Ind. Engng Chem. Fundam. Vol. 14, pp. 337-347.

[23] Andreussi, P. and Bendiksen, K. 1989. An investigation of void fraction in liquid slugs for horizontal and inclined gas-liquid pipe flow. Int. J. of Multiphase Flow, 15 (6), 937-946. 
[24] Nicholson, M.K., Aziz, K., Gregory, G.A. 1978. Intermittent two phase flow in horizontal pipes: predictive models. Can. J. Chem. Eng. 56, 653663.

[25] Nydal, O.J., Pintus, S., Andreussi, P. 1992. Statistical characterization of slug flow in horizontal pipes. Int. J. Multiphase Flow 18, pp. 439-453.

[26] Brill, J.P., Schmidt, Z., Coberly, W.A., Herring, J.D., Moore, D.W. 1981. Analysis of two-phase tests in large diameter flow lines in Prudhoe Bay Field. Soc. Petrol. Eng. J., 363-377. 